\title{
An Overview of Oral Health Related Quality of Life
}

\section{Lucas Guimaraes Abreu*}

Federal University of Minas Gerais, Brazil

\section{Introduction}

Quality of life (QoL) is defined as an individual's perception of his/her position in life in the context of the culture and value systems in which he/she lives and in relation to his/her goals, expectations, standards and concerns [1]. This concept has two fundamental elements: multidimensionality and subjectivity. The former refers to the coverage of a broad range of content, including physical, functional, emotional and social well-being. The latter refers to the fact that quality of life can only be understood from the patient's perspective [2]. Taking into account those elements and considering the dynamic nature of quality of life, two individuals, showing similar health status, may present different quality of life perspectives depending on their experiences, expectations and perceptions [3]. Therefore, the relation between symptoms and well-being and quality of life is neither simple nor direct. Nevertheless, the assumption of quality of life as the discrepancy between patients' expectations and experience gives an explanation on how it can be assessed. Expectations are learnt from experience. If on one hand, treatment success is likely to result in positive expectations of health services, on the other hand, unmet expectations leads to dissatisfaction and unfavourable outcomes [4].

The concept of oral health related quality of life (OHRQoL) regards how oral outcomes impact on individuals' well-being and quality of life [5]. Over the past two decades, dental research has given increasing attention to the assessment of patients' quality of life and many studies regarding this issue have been published in the dental literature providing a helpful source of information to researchers, oral health decision makers and clinicians. Oral outcomes were traditionally evaluated through clinical criteria based on the perceptions of clinicians, who were unable to determine the real impact of oral diseases and their treatments on individuals' daily routine [6]. Clinical criteria are undeniably relevant. However, the functional, emotional and social impacts of oral outcomes on individuals' lives are equally important and, therefore, should not be ignored anymore [7]. Thus, when OHRQoL measures are adopted alongside the traditional clinical methods of assessing oral health status, a more comprehensive evaluation of the effect of oral outcomes on the physical and psychosocial dimensions of people's well-being becomes possible and feasible [8].

\section{OHRQoL Instruments}

OHRQoL has been measured through quality of life instruments or questionnaires [9]. The administration of those instruments may be carried out using different strategies including direct interview, selfcompletion questionnaires and proxy responders, when the assessed individuals are unable to answer the questions [10]. However, the most popular method is the individual-completed questionnaire [11]. There are two main sorts of instruments that may be used. Both choices have strengths and shortcomings [10]. Generic instruments provide a summary of quality of life. These instruments allow comparison among different domains of quality of life and also comparison across populations. However, they may lack the ability to detect small changes in health status, which limits their use. Specific instruments, on the other hand, focus on issues related to single disease states or groups of patients. These instruments evaluate life quality in individuals suffering from a specific disease. They have also been used in subgroups of people such as children. Nevertheless, they cannot be adopted to examine quality of life across populations or other disease states which constitutes a limitation $[10,12]$. Researchers have conducted studies to determine the responsiveness of such measures or their ability to detect changes when a patient improves his/her health status [13] The research community has also witnessed attempts to determine what constitutes a meaningful change. A clinically important difference is an alteration considered significant by the patient and the minimum important difference is a threshold value for such a change [14].

\section{OHRQoL and Pediatric Dentistry}

For many years, OHRQoL measures have been developed to examine the impact of oral outcomes on adults' lives [15,16]. A study conducted in Brazil found a negative correlation between dental caries and quality of life of adult individuals with the main effect being upon the social, psychological and environmental subscales [17]. Similar results were found in a study carried out in India in which dental caries, among other oral conditions, had the greatest adverse impact on the quality of life of rural and urban adults [18]. The association between poor oral health and a negative impact on people's life is also an issue in developed countries such as Norway [19]. More recently, interest has centred on the development of tools for young individuals $[20,21]$. Several studies these tools have shown that oral disorders such as tooth agenesis [22], dental caries [23], fluorosis [24] and traumatic dental injury [25] have a negative impact on children's and adolescents' quality of life. When infants are evaluated, it is also important to assess the perceptions of parents and caregivers [26] and the impact of oral disorders on young individuals' families [27] For instance, families of adolescents who present more severe traumatic dental injury are more likely to report an adverse effect on OHRQoL than families of adolescents who present only enamel fractures or no history of dental trauma. The main repercussions are in the parental activities and parental emotions subscales which can lead to family conflicts [28]. Malocclusion also negatively affects adolescents' quality of life. Individuals with more severe discrepancies present a more severe impact on OHRQoL when compared with their counterparts with less severe anomalies [29]. Individuals' families are also negatively impacted [30].

Researchers have also an interest in the assessment of the impact of dental treatment on individuals' quality of life. OHRQoL measures have been used to determine whether therapeutic dental interventions improve patients' lives [31]. Results of cross-sectional and longitudinal evaluations show that dental caries treatment has a positive impact

*Corresponding author: Lucas Guimaraes Abreu, Assistant Professor, Department of Pediatric Dentistry and Orthodontics, Federal University of Minas Gerais, Brazil, Tel: +55 31 3409-5000; E-mail: lucasgabreu01@gmail.com

Received: October 30, 2015; Accepted: November 07, 2015; Published: November 14,2015

Citation: Abreu LG (2015) An Overview of Oral Health Related Quality of Life. Oral health case Rep 1:e105. doi:10.4172/2471-8726.1000e105

Copyright: ( 2015 Abreu LG. This is an open-access article distributed under the terms of the Creative Commons Attribution License, which permits unrestricted use, distribution, and reproduction in any medium, provided the original author and source are credited. 
on children's and adolescents' quality of life $[32,33]$. The impact is also positive for children's parents/caregivers [34] and their families [35]. Orthodontic treatment has also a significant effect on children's and adolescents' OHRQoL. During the first months following the placement of fixed appliances, the OHRQoL of an infant deteriorates due to a combination of pain and functional limitations [36].

However, when orthodontic therapy is completed, these individuals' quality of life is substantially improved [37]. Positive repercussions have also been observed for young individuals' parents/caregivers [38] and families [39].

\section{OHRQoL and Practice}

Knowledge obtained from OHRQoL evaluations could be thoroughly applied by health policy makers in order to justify the allocation of financial resources in the development of oral health programs. Given that oral disorders have a negative impact on individuals' quality of life, the expansion of oral health services may contribute to relieve suffering caused by oral diseases and therefore improve people's lives $[7,40]$. In places where oral health services have already been consolidated, quality of life assessments may be helpful in routine practice to prioritize preferences and improve communication between the individual submitted to treatment and the clinician [41].

\section{References}

1. Study protocol for the World Health Organization project to develop a Quality of Life assessment instrument (WHOQOL). Qual Life Res 2: 153-159.

2. Cella DF (1994) Quality of life: concepts and definition. J Pain Symptom Manage 9: 186-192.

3. Allison PJ, Locker D, Feine JS (1997) Quality of life: a dynamic construct. Soc Sci Med 45: 221-230.

4. Carr AJ, Gibson B, Robinson PG (2001) Measuring quality of life: Is quality of life determined by expectations or experience? BMJ 322: 1240-1243.

5. Sischo L, Broder HL (2011) Oral health-related quality of life: what, why, how, and future implications. J Dent Res 90: 1264-1270.

6. Locker D (2004) Oral health and quality of life. Oral Health Prev Dent 2 Suppl 1: $247-253$.

7. Feu D, Quintão CCA, Miguel JAM (2010) Quality of life instruments and their role in orthodontics. Dental Press J Orthod 15: 61-70.

8. Lawrence HP, Thomson WM, Broadbent JM, Poulton R (2008) Oral healthrelated quality of life in a birth cohort of 32-year olds. Community Dent Oral Epidemiol 36: 305-316.

9. Antunes LA, Leão AT, Maia LC (2012) [The impact of dental trauma on quality of life of children and adolescents: a critical review and measurement instruments]. Cien Saude Colet 17: 3417-3424.

10. Guyatt GH, Feeny DH, Patrick DL (1993) Measuring health-related quality of life. Ann Intern Med 118: 622-629.

11. Cunningham SJ, Hunt NP (2001) Quality of life and its importance in orthodontics. J Orthod 28: 152-158.

12. Camilleri-Brennan J, Steele RJ (1999) Measurement of quality of life in surgery J R Coll Surg Edinb 44: 252-259.

13. Husted JA, Cook RJ, Farewell VT, Gladman DD (2000) Methods for assessing responsiveness: a critical review and recommendations. J Clin Epidemiol 53: 459-468.

14. Jaeschke R, Singer J, Guyatt GH (1989) Measurement of health status. Ascertaining the minimal clinically important difference. Control Clin Trials 10 : 407-415

15. Slade GD, Spencer AJ (1994) Development and evaluation of the Oral Health Impact Profile. Community Dent Health 11: 3-11.

16. Leao A, Sheiham A (1996) The development of a socio-dental measure of dental impacts on daily living. Community Dent Health 13: 22-26.
17. Costa Sde M, Vasconcelos M, Abreu MH (2013) [Impact of dental caries on quality of life among adults resident in greater Belo Horizonte, State of Minas Gerais, Brazil]. Cien Saude Colet 18: 1971-1980.

18. Sanadhya S, Aapaliya P, Jain S, Sharma N, Choudhary G, et al. (2015) Assessment and comparison of clinical dental status and its impact on ora health-related quality of life among rural and urban adults of Udaipur, India: A cross-sectional study. J Basic Clin Pharm 6: 50-58.

19. Dahl KE, Wang NJ, Ohrn K (2012) Does oral health matter in people's daily life? Oral health-related quality of life in adults $35-47$ years of age in Norway. Int $J$ Dent Hyg 10: 15-21.

20. Pahel BT, Rozier RG, Slade GD (2007) Parental perceptions of children's ora health: the Early Childhood Oral Health Impact Scale (ECOHIS). Health Qual Life Outcomes 5: 6.

21. Broder HL, McGrath C, Cisneros GJ (2007) Questionnaire development: face validity and item impact testing of the Child Oral Health Impact Profile. Community Dent Oral Epidemiol 35 Suppl 1: 8-19.

22. Kotecha S, Turner PJ, Dietrich T, Dhopatkar A (2013) The impact of tooth agenesis on oral health-related quality of life in children. J Orthod 40: 122-129.

23. Krisdapong S, Prasertsom P, Rattanarangsima K, Sheiham A (2013) Impacts on quality of life related to dental caries in a national representative sample of Thai 12-and 15-year-olds. Caries Res 47: 9-17.

24. Tellez M, Santamaria RM, Gomez J, Martignon S (2012) Dental fluorosis, dental caries, and quality of life factors among schoolchildren in a Colombian fluorotic area. Community Dent Health 29: 95-99.

25. Bendo CB, Paiva SM, Varni JW, Vale MP (2014) Oral health-related quality of life and traumatic dental injuries in Brazilian adolescents. Community Dent Oral Epidemiol 42: 216-223.

26. Barbosa TD, Gavião MB (2012) Validation of the Parental-Caregiver Perceptions Questionnaire: agreement between parental and child reports. $J$ Public Health Dent.

27. Abanto J, Paiva SM, Raggio DP, Celiberti P, Aldrigui JM, et al. (2012) The impact of dental caries and trauma in children on family quality of life. Community Dent Oral Epidemiol 40: 323-331.

28. Bendo CB, Paiva SM, Abreu MH, Figueiredo LD, Vale MP (2014) Impact of traumatic dental injuries among adolescents on family's quality of life: a population-based study. Int J Paediatr Dent 24: 387-396.

29. Scapini A, Feldens CA, Ardenghi TM, Kramer PF (2013) Malocclusion impacts adolescents' oral health-related quality of life. Angle Orthod 83: 512-518.

30. Abreu LG, Melgaço CA, Abreu MH, Lages EM, Paiva SM (2015) Effect of malocclusion among adolescents on family quality of life. Eur Arch Paediatr Dent 16: 357-363.

31. Malden PE, Thomson WM, Jokovic A, Locker D (2008) Changes in parentassessed oral health-related quality of life among young children following dental treatment under general anaesthetic. Community Dent Oral Epidemiol 36: 108-117.

32. Chukwumah NM, Folayan MO, Oziegbe EO, Umweni AA (2015) Impact of dental caries and its treatment on the quality of life of 12- to 15-year-old adolescents in Benin, Nigeria. Int J Paediatr Dent.

33. de Paula JS, Sarracini KL, Meneghim MC, Pereira AC, Ortega EM, et al. (2015) Longitudinal evaluation of the impact of dental caries treatment on oral healthrelated quality of life among schoolchildren. Eur J Oral Sci 123: 173-178.

34. Cantekin K, Yildirim MD, Cantekin I (2014) Assessing change in quality of life and dental anxiety in young children following dental rehabilitation under general anesthesia. Pediatr Dent 36: 12E-17E.

35. Thomson WM, Malden PE (2011) Assessing change in the family impact of caries in young children after treatment under general anaesthesia. Acta Odontol Scand 69: 257-262.

36. Zhang M, McGrath C, Hagg U (2008) Changes in oral health-related quality of life during fixed orthodontic appliance therapy. Am J Orthod Dentofacial Orthop 133: $25-29$.

37. Chen M, Wang DW, Wu LP (2010) Fixed orthodontic appliance therapy and its impact on oral health-related quality of life in Chinese patients. Angle Orthod 80: 49-53.

38. Abreu LG, Melgaço CA, Lages EM, Abreu MH, Paiva SM (2014) Parents' and 
caregivers' perceptions of the quality of life of adolescents in the first 4 months of orthodontic treatment with a fixed appliance. J Orthod 41: 181-187.

39. Abreu LG, Melgaço CA, Abreu MH, Lages EM, Paiva SM (2014) Impact of the first eight months of orthodontic treatment with a fixed appliance on the families of adolescent patients. Angle Orthod 84: 1074-1078.
40. McGrath C, Broder H, Wilson-Genderson M (2004) Assessing the impact of oral health on the life quality of children: implications for research and practice. Community Dent Oral Epidemiol 32: 81-85.

41. Higginson IJ, Carr AJ (2001) Measuring quality of life: Using quality of life measures in the clinical setting. BMJ 322: 1297-1300. 